\title{
Platelets of patients with chronic kidney disease demonstrate deficient platelet reactivity in vitro
}

Esther R van Bladel ${ }^{1 \dagger}$, Rosa L de Jager ${ }^{2 \dagger}$, Daisy Walter ${ }^{1}$, Loes Cornelissen ${ }^{1}$, Carlo A Gaillard ${ }^{2,3}$, Leonie A Boven², Mark Roest ${ }^{1}$ and Rob Fijnheer ${ }^{1,2^{*}}$

\begin{abstract}
Background: In patients with chronic kidney disease studies focusing on platelet function and properties often are non-conclusive whereas only few studies use functional platelet tests. In this study we evaluated a recently developed functional flow cytometry based assay for the analysis of platelet function in chronic kidney disease.

Methods: Platelet reactivity was measured using flow cytometric analysis. Platelets in whole blood were triggered with different concentrations of agonists (TRAP, ADP, CRP). Platelet activation was quantified with staining for P-selectin, measuring the mean fluorescence intensity. Area under the curve and the concentration of half-maximal response were determined.

Results: We studied 23 patients with chronic kidney disease (9 patients with cardiorenal failure and 14 patients with end stage renal disease) and 19 healthy controls. Expression of P-selectin on the platelet surface measured as mean fluorescence intensity was significantly less in chronic kidney disease patients compared to controls after maximal stimulation with TRAP (9.7 (7.9-10.8) vs. 11.4 (9.2-12.2), $\mathrm{P}=0.032)$, ADP (1.6 (1.2-2.1) vs. 2.6 (1.9-3.5), $P=0.002)$ and CRP (9.2 (8.5-10.8) vs. 11.5 (9.5-12.9), $P=0.004)$. Also the area under the curve was significantly different. There was no significant difference in half-maximal response between both groups.

Conclusion: In this study we found that patients with chronic kidney disease show reduced platelet reactivity in response of ADP, TRAP and CRP compared to controls. These results contribute to our understanding of the aberrant platelet function observed in patients with chronic kidney disease and emphasize the significance of using functional whole blood platelet activation assays.
\end{abstract}

Keywords: Platelet activation, Haemodialysis, Cardiorenal syndrome, End-stage renal disease

\section{Background}

In chronic kidney disease both bleeding and thrombotic complications are observed. It has been hypothesized that this disturbed balance between pro- and antihaemostatic factors is involved in the high morbidity and mortality reported in chronic kidney disease [1-4]. Early stages of chronic kidney disease are typically associated with a prothrombotic tendency, whereas in its more advanced stage patients also suffer from a bleeding diathesis [5].

\footnotetext{
* Correspondence: r.fijnheer@meandermc.nl

${ }^{\dagger}$ Equal contributors

${ }^{1}$ Department of Clinical Chemistry and Hematology, University Medical Center Utrecht, Heidelberglaan 100, 3584 CX, Utrecht, The Netherlands ${ }^{2}$ Department of Internal Medicine and Laboratory Medicine, Meander Medical Center, Utrechtseweg 160, 3800 BM, Amersfoort, The Netherlands Full list of author information is available at the end of the article
}

Bleeding tendency of patients is characterized by haemorrhagic symptoms and by prolongation of bleeding time [6]. The cause of bleeding in this group of patients has been elaborated in the past and the pathogenesis seems multifactorial. It is suggested that abnormal platelet function is a major contributor, since haemorrhage occurs despite a coagulation profile of normal or elevated levels of coagulation factors and normal platelet counts $[4,6]$. Platelet dysfunction may be the result of decreased dense granule content, decreased sensitivity to platelet agonists, abnormal expression of platelet glycoproteins, defective arachidonate metabolism and depressed prostaglandin metabolism as well as impaired platelet adhesiveness. Platelet dysfunction is thought to be caused by the action of uremic toxins, anemia, increased nitric oxide production, von Willebrand factor abnormalities and the use of

\section{() Biomed Central}


medication like aspirin, non-steroidal anti-inflammatory drugs and $\beta$-lactam antibiotics $[4,6-8]$. Besides an increased bleeding risk, a variety of thrombotic complications are observed in patients with chronic renal failure, including coronary heart disease, cerebrovascular disease, peripheral vascular disease and heart failure. Already in mild to moderate chronic kidney disease an increased risk of cardiovascular events and higher mortality have been reported [1,2,9-12].

The balance between thrombosis and bleeds is disturbed in chronic kidney disease. Functional platelet tests are needed to obtain more insight into this balance. However, up to know only a minority of the studies used functional platelet tests and results are non-conclusive $[6,13]$. This is probably due to in vitro artifacts as a result of the procedure of platelet isolation, influence of plasma proteins and influence of hematocrit. Therefore we have set up this study with a recently developed, flow cytometer based, functional platelet assay in whole blood, in which these factors are not of influence. With this assay we assessed platelet reactivity in patients with end stage renal disease and cardiorenal syndrome. Both platelet sensitiveness as well as maximal activation of platelets in response to 3 different platelet stimuli was measured, providing an explanation for the disturbed haemostatic balance in patients with renal failure.

\section{Methods}

\section{Subjects}

Patients were selected from the out-patient clinic of the Meander Medical Center in Amersfoort for this prospective, observational study. Two groups of patients with chronic kidney disease were recruited. The first group consisted of patients with end stage renal disease receiving hemodialysis [14]. In patients on hemodialysis, blood samples were collected before and also immediately after hemodialysis (pre versus post dialysis). All samples were collected using citrate tubes and mixed gently. The second group consisted of patients with cardiorenal syndrome, defined as coexistence of chronic kidney disease and chronic heart failure [15]. Chronic kidney disease in this group was defined as eGFR $<70 \mathrm{ml} / \mathrm{min}$ without requirement of hemodialysis. Chronic heart failure was defined as NYHA class II or higher, based on symptoms, signs and objective abnormality on echocardiography [16]. Controls included subjects recruited from among healthy hospital staff, healthy subjects attending the hospital for control follow up and healthy partners of patients. Patients were excluded from the study based on the following criteria: clinical signs of infection, malignancy, primary haemostatic disorders unrelated to uremia, treatment with immunosuppressive drugs, use of antiplatelet agents (except aspirin) such as clopidogrel, dipyridamole or non-steroidal anti-inflammatory drugs and the inability to provide informed consent. The protocol was approved by the local medical ethical committee of Meander Medical Center Amersfoort and both patients and control volunteers gave written informed consent to participate in the study.

\section{Blood sampling and processing}

In patients on haemodialysis, the samples were collected before starting the haemodialysis and immediately after the procedure. The first sample was taken from the afferent line directly after inserting the needle in the fistula. The second sample was taken directly after dialysis from the efferent line out of the dialysis machine. In control subjects peripheral venous blood samples were collected from the antecubital vein using 21 gauge needles. A total of $4.5 \mathrm{~mL}$ blood was drawn into vacutainer tubes containing $0.5 \mathrm{~mL} \mathrm{3.2 \%} \mathrm{sodium-citrate} \mathrm{solution} \mathrm{as} \mathrm{anticoagulant}$ and mixed gently. Blood cell count assays were performed using a haematology analyzer (Sysmex, Etten-Leur, The Netherlands). Hemoglobin, hematocrit, and platelet count were noted.

\section{Materials}

For our samples we used HEPES-buffered saline (HBS) containing $10 \mathrm{mM}$ HEPES (BDH biochemical, UK), $150 \mathrm{mM}$ $\mathrm{NaCl}$ (Sigma-Aldrich, Zwijndrecht, the Netherlands), $1 \mathrm{mM}$ $\mathrm{MgSO}_{4}$ (Riedel de Haën, Hannover, Germany) and $5 \mathrm{mM} \mathrm{KCl}$ (Riedel de Haën), with a pH of 7.4. Fixation was done with a fixation buffer containing $0.2 \%$ formaldehyde (Calbiochem, Merck, Darmstadt, Germany) in $0.9 \% \mathrm{NaCL}$ (Sigma-Aldrich). Used fluorochromelabeled ligands were anti-CD42b fluorescein isothiocyanate (FITC)-labeled mouse antihuman antibody (BD Pharmingen $^{\mathrm{Tm}}$, San Diego, California, USA) and antiCD62P phycoerythrin (PE)-labeled mouse antihuman antibody (BD Pharmingen ${ }^{\mathrm{Tx}}$ ). Adenosine diphosphate (ADP) (Roche, Almere, the Netherlands) was used as agonist, as well as thrombin-receptor-associatedpeptide (TRAP) (Bachem, Weil am Rhein, Germany) and cross-linked collagen related peptide (CRP) was a generous gift of R. Farndale (Cambridge, United Kingdom).

\section{Platelet reactivity}

Assays were performed as described before [17]. In short, $5 \mu \mathrm{L}$ of whole blood was added to tubes containing $50 \mu \mathrm{L}$ of HBS, fluorochrome-labeled ligands and serial dilutions of agonists. Anti-CD42b FITC-labeled monoclonal antibodies were used as an activation-independent platelet marker. PE-labeled anti-CD62P was used as an activationdependent marker. For each agonist eight different concentrations were used, with four times dilution steps between each sample. Concentrations of TRAP were 0.038 to $625 \mu \mathrm{mol} / \mathrm{L}$, ADP 0.008 to $125 \mu \mathrm{mol} / \mathrm{L}$, and CRP 0.2 to $2500 \mathrm{ng} / \mathrm{mL}$. After incubation at room temperature for 20 minutes, platelets were fixed by the addition of $500 \mu \mathrm{L}$ 
fixative ( $0.2 \%$ paraformaldehyde). Subsequently, samples were 3.5 times diluted with the same fluid for flow cytometric analysis. Samples were analyzed by flow cytometry on a Epics XL-MCL Flow Cytometer (Beckman Coulter, Miami, Florida, USA) and EXPO 32 MultiCOMP Software (Beckman Coulter) was used to process the data. The platelet population was identified by forward and $90^{\circ}$ side scatter properties in combination with a positive CD42b signal. Isotype control antibodies were used to correct for aspecific binding. The mean fluorescence intensity (MFI) of all platelets is expressed in arbitrary units (AU).

\section{Statistical analysis}

GraphPad software version 4.0 for Windows (GraphPad Software, San Diego, California USA) was used to draw graphs and to calculate EC50. EC50 is defined as the concentration of the agonist needed to achieve an effect on the platelets halfway between the maximum and minimum. Area under the curve (AUC) was calculated in SPSS by adding up the outcome minus basal activation outcome of all concentrations points. The data were analyzed by logistic regression for scaled data. For comparisons of nominal variables a Chi-square cross tabulation with a Fisher's Exact test was used. Statistical analyses were undertaken using SPSS software version 15.0 (SPSS Inc, Chigaco, Illinois). A P-value of $<0.05$ was considered as statistically significant. Values are given as median with interquartile range (IQR) if not noted otherwise.

\section{Results}

\section{Patient characteristics}

Twenty-three patients with chronic kidney disease and 19 healthy controls were included. In the chronic kidney disease group, we included 9 patients with cardio renal syndrome and 14 patients with end stage renal failure on hemodialysis (analyzed before and immediate after dialysis). Clinical and laboratory characteristics are listed in Table 1. Age was significantly higher in patients (78 years (64-83)) compared to controls (62 years (48-71)). As expected hemoglobin and hematocrit level were significantly lower in cardio renal syndrome patients compared to controls. There were no significant differences in platelet count. The etiology of chronic kidney disease was divers: hypertension $(n=7)$, diabetic nephropathy $(\mathrm{n}=4)$, membranous glomerulopathy $(\mathrm{n}=1)$, rapid progressive IgA nephropathy $(\mathrm{n}=1)$, chronic pyelonephritis $(n=1)$, polycystic nephropathy $(n=1)$, nephrosclerosis $(n=1)$ or unknown cause $(n=7)$. The etiology of chronic heart failure was of ischemic origin $(n=5)$, valvular heart disease $(n=3)$ or unknown $(n=1)$.

\section{Platelet reactivity}

Expression of P-selectin on the platelet surface measured as MFI was significantly lower in chronic kidney disease
Table 1 Baseline characteristics in patients with chronic kidney disease and controls

\begin{tabular}{lccccc}
\hline Baseline characteristics & Controls & & CKD & P-value \\
\cline { 2 - 2 } & $\mathbf{N}=\mathbf{1 9}$ & & $\mathbf{N}=\mathbf{2 3}$ & \\
\hline Age, y (IQR) & $62(48-71)$ & & $78(64-83)$ & 0.043 \\
\hline Male, $\mathrm{n}(\%)$ & $13(68.4)$ & $15(65.2)$ & 0.755 \\
\hline Hemoglobin, mmol/L (IQR) & $9.4(9.0-9.9)$ & $7.2(6.7-7.8)$ & 0.006 \\
\hline Hematocrit, L/L (IQR) & $0.44(0.43-0.47)$ & $0.36(0.34-0.38)$ & 0.001 \\
\hline Platelet count, 109/L (IQR) & $210(150-240)$ & $187(160-225)$ & 0.223 \\
\hline Hemodialysis, $\mathrm{n}(\%)$ & $\mathrm{NA}$ & $14(60.9)$ & - \\
\hline Cardiorenal syndrome, $\mathrm{n}(\%)$ & $\mathrm{NA}$ & $9(39.1)$ & - \\
\hline EPO use, $\mathrm{n}(\%)$ & $\mathrm{NA}$ & $5(21.7)$ & - \\
\hline Aspirin use, $\mathrm{n}(\%)$ & 0 & $11(47.8)$ & - \\
\hline CKD & & &
\end{tabular}

$C K D$ chronic kidney disease, $I Q R$ inter quartile range, EPO erythropoietin.

patients compared to controls after maximal stimulation with TRAP (9.7 (7.9-10.8) vs. 11.4 (9.2-12.2), $\mathrm{P}=0.032)$, ADP (1.6 (1.2-2.1) vs. $2.6(1.9-3.5), \mathrm{P}=0.002)$ and CRP (9.2 (8.5-10.8) vs. $11.5(9.5-12.9), \mathrm{P}=0.004)$. (Figure 1 and Table 2). Maximal P-selectin expression in response to different agonist correlated significantly with each other (Spearmann's Rho correlation TRAP and ADP 0.684 with $p<0.001$; TRAP and CRP 0.538 with $p<0.001$; ADP and CRP 0.475 with $p=0.001$ ). Table 2 shows that the EC50 was not different between chronic kidney disease patients and controls.

Chronic kidney disease patients showed significantly lower platelet reactivity as compared to healthy control subjects for TRAP (AUC : 39.5 (32.9-44.4) vs. 47.1 (41.1-54.2), $\mathrm{P}=0.01$ ) and ADP (AUC: 5.8 (3.8-7.3) vs. 8.9 (7.9-12.2), $\mathrm{P}=0.002$ ) when measured with AUC (Table 2). Stimulation with CRP (AUC: 23.4 (18.9-34.79) vs. 30.3 (22.1-41.9), $\mathrm{p}=0.06)$ does not show a difference in reactivity between the groups.

Since age was significant lower in the control group we adjusted for this in a regression analysis. The significant difference in MFI and AUC between chronic kidney disease patients and controls after maximal stimulation remained significant (Table 2). There was no significant difference between patients with cardiorenal failure and patients with end stage renal failure.

In the chronic kidney disease group almost half of the patients used aspirin as anti-platelet therapy. Platelet reactivity in this group does not show a difference between aspirin users and patients without aspirin. This accounts for all outcome measurements.

\section{Pre-versus-post dialysis}

To rule out an activating effect of the hemodialysis procedure on baseline platelet activation we studied platelet activation before and immediate after dialysis. The platelet sensitivity (EC50) for TRAP, ADP and CRP did not 


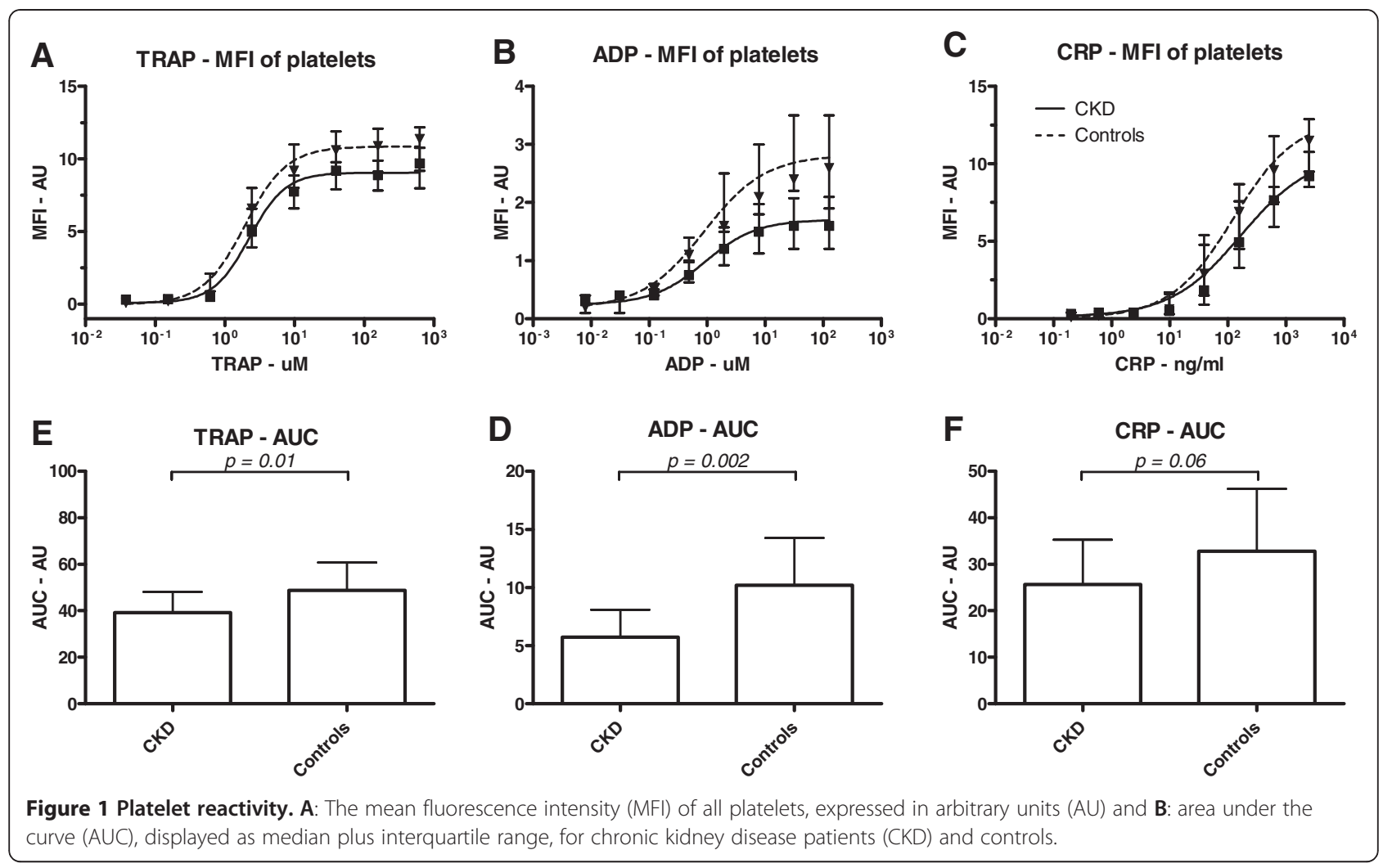

differ between patients pre- and post dialysis. There was no difference between the maximum reached effect and AUC on platelet activation when comparing patients pre- and post dialysis (data not shown).

\section{Discussion}

The aim of this study was to investigate the relation between platelet function and kidney failure in patients with end stage renal disease and cardiorenal syndrome using a flow cytometer based, functional platelet assay. We show that P-selectin expression after stimulation with ADP, CRP and TRAP is lower in patients with chronic kidney disease as compared to healthy controls. Furthermore, we demonstrate that the EC50 was not different between groups. This means that platelet sensitivity itself is not affected for the different agonists, but the maximal platelet response is significantly lower.

Platelets were activated with 3 different stimuli. We chose for the agonists TRAP, ADP and CRP, which stimulate the three major physiological platelet activation pathways. TRAP activates the thrombin receptor Proteinase Activated Receptor 1 (PAR-1) on platelets. ADP is normally present

Table 2 Results platelet activation

\begin{tabular}{lcccc}
\hline & Controls & CKD & P-value & P-value \\
\cline { 2 - 3 } & $\mathbf{N}=\mathbf{1 9}$ & $\mathbf{N}=\mathbf{2 3}$ & Adjusted for age \\
\hline Maximal MFI TRAP, AU (IQR) & $11.4(9.2-12.2)$ & $9.7(7.9-10.8)$ & 0.032 & 0.095 \\
\hline Maximal MFI ADP, AU (IQR) & $2.6(1.9-3.5)$ & $1.6(1.2-2.1)$ & 0.002 & 0.004 \\
\hline Maximal MFICRP, AU (IQR) & $11.5(9.5-12.9)$ & $9.2(8.5-10.8)$ & 0.004 & 0.010 \\
\hline EC50 TRAP, $\mu M(I Q R)$ & $1.9(1.5-2.5)$ & $2.3(1.8-2.6)$ & 0.372 & 0.182 \\
\hline EC50 ADP, $\mu M(I Q R)$ & $0.9(0.6-1.1)$ & $0.89(0.7-1.1)$ & 0.544 & 0.597 \\
\hline EC50 CRP, ng/ml (IQR) & $120(46.7-312.7)$ & $116.1(46.1-270.5)$ & 0.955 & 0.660 \\
\hline AUC TRAP, AU (IQR) & $47.1(41.1-54.2)$ & $39.5(32.9-44.4)$ & 0.012 & 0.023 \\
\hline AUC ADP, AU (IQR) & $8.9(7.9-12.2)$ & $5.8(3.8-7.3)$ & 0.002 & 0.003 \\
\hline AUC CRP, AU (IQR) & $30.3(22.1-41.9)$ & $23.4(18.9-34.7)$ & 0.063 & 0.322 \\
\hline
\end{tabular}

MFI Mean fluorescence intensity, $A U$ arbitrary units, IQR inter quartile range, EC50 concentration of agonist leading to a half maximal P-selectin expression, AUC Area under the curve. 
in platelet dense granules. Upon platelet activation, ADP is released to activate nearby platelets via the P2Y receptors. CRP activates the receptor glycoprotein VI, the major collagen receptor on platelets. So, all 3 stimuli are of physiological importance.

P-selectin is found in the $\alpha$-granula of platelets. A deficiency in $\alpha$-granula could lead to ineffective haemostasis. Two different explanations are possible for the deficient platelet $\alpha$-granula release found in chronic kidney disease. This could be due to depletion of $\alpha$-granula itself, or due to a deficiency in the release of $\alpha$-granula. An impaired $\alpha$-granule release has already been reported in uraemia [18]. This is further supported by the recent observations of Schoorl et al. of an increase in platelets depleted from granules in patients undergoing chronic haemodialysis [19]. Nevertheless, we cannot exclude an impairment of release.

The clinical bleeding tendency in uremic patients received much attention [7]. Haemo- or peritoneal dialysis was found to improve haemostasis without correcting platelet aggregation defects. In contrast, compensatory mechanisms in the form of high von Willebrand factor (VWF) levels preserved relatively normal adhesion of uremic platelets to injured vessel wall models [20]. Moreover, as soon as the hematocrit - determining the red blood cell-mediated radial transport of blood platelets towards the vessel wall - was corrected by recombinant erythropoietin, clinical bleeding became less prominent. In contrast, thromboembolic/cardiovascular morbidity remains an important problem in these patients [21]. Especially in cardiorenal failure, there seems no or little benefit from treatment with antiplatelet agents, whilst risk of bleeding may increase [22]. Even though reports on platelet reactivity in patient with chronic kidney disease show conflicting results [23], it has been attributed to an acquired thrombocytopathy characterized by decreased aggregation of platelets in response to stimuli. There are only a few studies that used functional tests to study platelet function in chronic kidney disease. Aggarwal et. al. found a higher P-selectin expression in patients with end stage renal disease receiving haemodialysis compared to healthy controls after stimulation with a single concentration of ADP $(0.2 \mu \mathrm{M})$. This suggests an increased reactivity [13]. Moal et. al performed a similar study in which ADP $(200 \mu \mathrm{M})$ and TRAP $(50 \mu \mathrm{M})$ in a single concentration were used to stimulate platelets in healthy controls and end stage renal disease patients receiving haemodialysis. They found a lower P-selectin expression in patients compared to controls, indicating reduced platelet reactivity in patients with chronic kidney disease [6]. Most assays used previously are influenced by in vitro artifacts, platelet isolation and are dependent on VWF or hematocrit. In our functional assay there is no role for VWF and hematocrit. Moreover, since fresh whole blood was used, and samples were fixated subsequent to stimulation, in vitro platelet activation was negligible. We couldn't find an immediate effect of haemodialysis, but long term dialysis and classical risk factors for athero-vascular disease could all be studied with this assay. Larger populations should be studied in order to find the factors influencing platelet reactivity in vivo.

In our study, aspirin did not suppress the expression of P-selectin on platelets. Considering the fact that aspirin function is related to inhibition of tromboxane formation and does not influences release of granules, this is an expected result. Moreover, our finding is in accordance with a study by Stumpf et. al., in which P-selectin expression on platelets did not show a difference between patients taking aspirin compared to non-aspirin users [24]. Further investigation is required to determine the influence of different drugs on platelet reactivity.

We here demonstrate that the flow cytometry based platelet activation assay can be used in clinical practice to study variables influencing platelet response in patients with renal failure. The assay is based on incubation with different agonists in whole blood and subsequent fixation. Platelets are sensitive for in vitro artifacts (especially platelet isolation, shear stress, $\mathrm{pH}$ and temperature). In our assay platelets are not isolated. The incubation in whole blood under standardized condition and the subsequent fixation step makes in vitro artifacts unlikely. When repeating the assay within healthy subjects at different blood collection moments, we find high reproducibility. Moreover, this assay can be used in routine clinical practice.

\section{Conclusion}

In conclusion, we found that patients with chronic kidney disease show reduced platelet reactivity in response of ADP, TRAP and CRP compared to controls. The defect is probably due to an $\alpha$-granule defect. Further investigation is required to determine a correlation between platelet reactivity and both renal function and the high mortality risk of patients with chronic kidney disease.

\section{Competing interests}

The authors declare that they have no competing interests.

\section{Author's contributions}

ERB participated in design of the study and interpretation of data, and contributed to drafting of the manuscript. RLJ participated in design of the study and in the performance of flow cytometry analysis, performed the statistical analysis and critically revised the manuscript. DW and LC carried out the FACS analysis, and participated in the statistical analysis of data and drafting of the manuscript. CAG, LAB and MR participated in the design of the study and critically revised the manuscript. RF designed the study, supervised its conduct and drafted the manuscript. All authors read and approved the final manuscript.

\section{Acknowledgements}

The authors have no acknowledgements to make. No funding was received for this study. 


\section{Author details}

${ }^{1}$ Department of Clinical Chemistry and Hematology, University Medical Center Utrecht, Heidelberglaan 100, 3584 CX, Utrecht, The Netherlands. 2Department of Internal Medicine and Laboratory Medicine, Meander Medical Center, Utrechtseweg 160, 3800 BM, Amersfoort, The Netherlands. ${ }^{3}$ Department of Nephrology, VU University Medical Center, Amsterdam, The Netherlands.

Received: 8 May 2012 Accepted: 22 August 2012

Published: 28 September 2012

\section{References}

1. Fried LF, Shlipak MG, Crump C, Bleyer AJ, Gottdiener JS, Kronmal RA, Kuller $L H$, Newman $A B$ : Renal insufficiency as a predictor of cardiovascular outcomes and mortality in elderly individuals. J Am Coll Cardiol 2003, 41:1364-1372.

2. Go AS, Chertow GM, Fan D, McCulloch CE, Hsu CY: Chronic kidney disease and the risks of death, cardiovascular events, and hospitalization. $N$ Engl J Med 2004, 351:1296-1305.

3. Sarnak MJ, Levey AS, Schoolwerth AC, Coresh J, Culleton B, Hamm LL, McCullough PA, Kasiske BL, Kelepouris E, Klag MJ, Parfrey P, Pfeffer M, Raij L, Spinosa DJ, Wilson PW: Kidney disease as a risk factor for development of cardiovascular disease: a statement from the American Heart Association Councils on Kidney in Cardiovascular Disease, High Blood Pressure Research, Clinical Cardiology, and Epidemiology and Prevention. Circulation 2003, 108:2154-2169.

4. Kaw D, Malhotra D: Platelet dysfunction and end-stage renal disease. Semin Dial 2006, 19:317-322.

5. Jalal DI, Chonchol M, Targher G: Disorders of hemostasis associated with chronic kidney disease. Semin Thromb Hemost 2010, 36:34-40.

6. Moal V, Brunet P, Dou L, Morange S, Sampol J, Berland Y: Impaired expression of glycoproteins on resting and stimulated platelets in uraemic patients. Nephrol Dial Transplant 2003, 18:1834-1841.

7. Noris M, Remuzzi G: Uremic bleeding: closing the circle after 30years of controversies? Blood 1999, 94:2569-2574.

8. Rios DR, Carvalho MG, Lwaleed BA, Silva AC Se, Borges KB, Dusse LM: Hemostatic changes in patients with end stage renal disease undergoing hemodialysis. Clin Chim Acta 2010, 411:135-139.

9. Collins AJ, Li S, Gilbertson DT, Liu J, Chen SC, Herzog CA: Chronic kidney disease and cardiovascular disease in the Medicare population. Kidney Int Supp/ 2003, 87:S24-S31.

10. Henry RM, Kostense PJ, Bos G, Dekker JM, Nijpels G, Heine RJ, Bouter LM Stehouwer CD: Mild renal insufficiency is associated with increased cardiovascular mortality: The Hoorn Study. Kidney Int 2002, 62:1402-1407.

11. Muntner P, He J, Hamm L, Loria C, Whelton PK: Renal insufficiency and subsequent death resulting from cardiovascular disease in the United States. J Am Soc Nephrol 2002, 3:745-753.

12. Nitta K: Pathogenesis and therapeutic implications of cardiorenal syndrome. Clin Exp Nephrol 2011, 15:187-194.

13. Aggarwal A, Kabbani SS, Rimmer JM, Gennari FJ, Taatjes DJ, Sobel BE, Schneider DJ: Biphasic effects of hemodialysis on platelet reactivity in patients with end-stage renal disease: a potential contributor to cardiovascular risk. Am J Kidney Dis 2002, 40:315-322.

14. Cockcroft DW, Gault MH: Prediction of creatinine clearance from serum creatinine. Nephron 1976, 16:31-41.

15. van der Putten $K$, Jie KE, Emans ME, Verhaar MC, Joles JA, Cramer MJ, Velthuis BK, Meiss L, Kraaijenhagen RJ, Doevendans PA, Braam B, Gaillard CA: Erythropoietin treatment in patients with combined heart and renal failure: objectives and design of the EPOCARES study. J Nephrol 2010, 23(4):363-368

16. Dickstein K, Cohen-Solal A, Filippatos G, McMurray JJ, Ponikowski P, Poole-Wilson PA, Strömberg A, van Veldhuisen DJ, Atar D, Hoes AW, Keren A, Mebazaa A, Nieminen M, Priori SG, Swedberg K, ESC Committee for Practice Guidelines (CPG): ESC guidelines for the diagnosis and treatment of acute and chronic heart failure 2008: the Task Force for the diagnosis and treatment of acute and chronic heart failure 2008 of the European Society of Cardiology. Developed in collaboration with the Heart Failure Association of the ESC (HFA) and endorsed by the European Society of Intensive Care Medicine (ESICM). Eur J Heart Fail 2008, 10:933-989.

17. van Bladel ER, Roest M, de Groot PG, Schutgens RE: Up-regulation of platelet activation in hemophilia A. Haematologica 2011, 96:888-895.
18. Kyrle PA, Stockenhuber F, Brenner B, Gössinger $H$, Korninger C, Pabinger I, Sunder-Plassmann G, Balcke $P$, Lechner K: Evidence for an increased generation of prostacyclin in the microvasculature and an impairment of the platelet alpha-granule release in chronic renal failure. Thromb Haemost 1988, 60:205-208.

19. Schoorl M, Bartels PCM, Gritters M, Fluitsma D, Musters R, Nubé MJ: Electron microscopic observation in case of platelet activation in a chronic haemodialysis subject. Hematol Rep 2011, 3:e15.

20. Zwaginga JJ, IJsseldijk MJ, Beeser-Visser N, De Groot PG, Vos J, Sixma JJ: High von Willebrand factor concentration compensates a relative adhesion defect in uremic blood. Blood 1990, 75:1498-1508.

21. Casserly LF, Dember LM: Thrombosis in end-stage renal disease. Semin Dial 2003, 16:245-256.

22. Palmer SC, Di Micco L, Razavian M, Craig JC, Perkovic V, Pellegrini F, Copetti M, Graziano G, Tognoni G, Jardine M, Webster A, Nicolucci A, Zoungas S, Strippoli GF: Effects of antiplatelet therapy on mortality and cardiovascular and bleeding outcomes in persons with chronic kidney disease. A systematic review and meta-analysis. Ann Intern Med 2012, 156:445-459.

23. Zwaginga JJ: Hemodialysis, erythropoietin and megakaryocytopoiesis: factors in uremic thrombocytopathy and thrombophilia. J Thromb Haemost 2004, 2(8):1272-1274.

24. Stumpf C, Lehner C, Eskafi S, Raaz D, Yilmaz A, Ropers S, Schmeisser A, Ludwig J, Daniel WG, Garlichs CD: Enhanced levels of CD154 (CD40 ligand) on platelets in patients with chronic heart failure. Eur J Heart Fail 2003, 5:629-637.

doi:10.1186/1471-2369-13-127

Cite this article as: van Bladel et al:: Platelets of patients with chronic kidney disease demonstrate deficient platelet reactivity in vitro. BMC Nephrology 2012 13:127.

\section{Submit your next manuscript to BioMed Central and take full advantage of:}

- Convenient online submission

- Thorough peer review

- No space constraints or color figure charges

- Immediate publication on acceptance

- Inclusion in PubMed, CAS, Scopus and Google Scholar

- Research which is freely available for redistribution 